\title{
Investigating the filled gel model in Cheddar cheese through use of Sephadex beads
}

\author{
L. M. Barden, ${ }^{*} \dagger$ J. A. Osborne,‡ D. J. McMahon, $\S$ and E. A. Foegeding ${ }^{* 1}$ \\ *Department of Food, Bioprocessing, and Nutrition Sciences, North Carolina State University, Raleigh 27695 \\ †Department of Food Science, University of Massachusetts Amherst, Amherst 01003 \\ łDepartment of Statistics, North Carolina State University, Raleigh 27695 \\ $\S$ Department of Nutrition, Dietetics, and Food Sciences, Utah State University, Logan 84322
}

\begin{abstract}
Cheese can be modeled as a filled gel whereby milkfat globules are dispersed in a casein gel network. We determined the filler effects using Sephadex beads (GE Healthcare Life Sciences, Pittsburgh, PA) as a model filler particle. Ideally, such a model could be used to test novel filler particles to replace milkfat in low-fat cheese. Low-filler (6\% particles), reduced-filler (16\%), and full-filler (33\%) cheeses were produced using either Sephadex beads of varying sizes (20 to $150 \mu \mathrm{m}$ diameter) or milkfat. Small- and large-strain rheological tests were run on each treatment at 8,12 , and $18 \mathrm{wk}$ after cheese manufacturing. Differences in rheological properties were caused primarily by the main effects of filler volume and type (milkfat vs. Sephadex), whereas filler size had no obvious effect. All treatments showed a decrease in deformability and an increase in firmness as filler volume increased above $25 \%$, although the beads exhibited a greater reinforcing effect and greater energy recovery than milkfat.
\end{abstract}

Key words: cheese, filled gel, Sephadex, particle size

\section{INTRODUCTION}

Low-fat cheese is known to differ markedly-and often undesirably - from its full-fat counterpart in sensory properties, including texture and flavor (Childs and Drake, 2009; Drake et al., 2010). Understanding how the milkfat content affects the structure and texture of cheese would allow developers to find acceptable substitutes to replace milkfat. One approach is to view cheese as a 2-phase composite material consisting of a casein gel phase with interdispersed lipid particles (Visser, 1991; Walstra, 2003; Yang et al., 2011). This suggests that a low-fat cheese structure similar to that of full-fat cheese can be made by (1) adding a filler

Received July 10, 2014.

Accepted November 22, 2014.

${ }^{1}$ Corresponding author: allen_foegeding@ncsu.edu particle at a phase volume equal to the fat phase, and (2) maintaining the casein gel phase as would be seen in the full-fat version. This approach fits under the theoretical framework of filled gel theory.

Cheddar cheese is suitable for analysis using filled gel models (Yang et al., 2011). Particle-filled gels or filled gels (also known as "gelled emulsions" and "composite gels") have been reviewed recently by Dickinson (2012). Most models are reductive, assume linear elastic behavior, and ignore viscoelastic effects (i.e., $\mathrm{G} \approx \mathrm{G}^{\prime}$; shear modulus and storage modulus, respectively). The general assumption is that the shear modulus of the filled gel $\left(\mathbf{G}_{\mathbf{m}+\mathrm{f}}\right)$ is proportional to the shear moduli of the gel matrix $\left(\mathbf{G}_{\mathbf{m}}\right)$ and filler phases $\left(\mathbf{G}_{\mathbf{f}}\right)$ and volume fractions of each phase $\left(\phi_{\mathrm{m}}+\phi_{\mathrm{f}}=1\right)$. Although $\mathrm{G}_{\mathrm{m}+\mathrm{f}}$ is easily measured, determining $G_{m}$ and $G_{f}$ in cheese is more problematic because it is hard to independently make the phases in such a state that they are similar to the states found in cheese. For monodispersed, spherical liquid droplets, $\mathrm{G}_{\mathrm{f}}$ is calculated based on droplet surface tension $(\gamma)$ and radius $(r)$ according to van Vliet (1988), as $\mathrm{G}_{\mathrm{f}}=2 \gamma / r$, but microscopic images of Cheddar cheese show a nonspherical shape (Yang et al., 2011) that prevents this simple calculation.

Filled gels are further differentiated based on whether the particles are interacting (active) or not interacting (inactive) with the gel matrix (Ring and Stainsby, 1982; van Vliet, 1988). Inactive fillers are not connected with the gel matrix and are treated as "holes" in the gel matrix, reducing the network volume and lowering G. Increasing the phase volume of an inactive filler should always decrease $\mathrm{G}$ because it essentially creates voids in the matrix. In contrast, an active filler can increase $\left(G_{f}>G_{m}\right)$, decrease $\left(G_{f}<G_{m}\right)$, or not change $\left(G_{f}=\right.$ $\left.\mathrm{G}_{\mathrm{m}}\right) \mathrm{G}$ according to relative magnitudes of filler and gel moduli (van Vliet, 1988; Chen and Dickinson, 1998, 1999). This makes the filler effect also dependent on temperature-associated changes in $\mathrm{G}_{\mathrm{f}}$ and $\mathrm{G}_{\mathrm{m}}$. For example, in experimental, milkfat-based Cheddar cheese of controlled protein-to-moisture ratios and controlled fat content, an increase in temperature caused a change 
in $\mathrm{G}_{\mathrm{f}}$ and $\mathrm{G}_{\mathrm{m}}$ such that, at $25^{\circ} \mathrm{C}, \mathrm{G}^{\prime}$ did not differ among cheeses varying in fat content from 3 to $33 \%$, indicating that $\mathrm{G}_{\mathrm{f}}$ was equal to $\mathrm{G}_{\mathrm{m}}$ at $25^{\circ} \mathrm{C}$ (Rogers et al., 2010).

The Kerner (1956) and van der Poel (1958) models are 2 of the earliest models and were developed to quantitatively predict the effect of a filler particle on the resulting composite gel moduli, assuming simple, isotropic systems and synthetic, spherical, monodispersed particles that did not aggregate (Ahmed and Jones, 1990). Therefore, the filled gel models needed to be validated in more complex, realistic systems; for example, biopolymer systems. To that effect, Ross-Murphy and Todd (1983) made composite gels of gelatin $(20 \% \mathrm{wt} / \mathrm{vol})$ and glass beads, which were available in spherical and cubical shapes, and ranged in filler volume from 0 to $80 \%$. Glass beads were used because they are nondeformable and exhibit perfect adhesion to the network at all strain levels, meaning they are active fillers. Ross-Murphy and Todd (1983) extended their analysis beyond the earlier studies on moduli to include fracture properties. Bracketing the effects of filler particle size, shape, and volume in forceextension failure "envelopes," Ross-Murphy and Todd (1983) showed that an increase in filler phase volume caused an increase in fracture stress but a decrease in fracture strain. This means the composite gels became stronger (increased fracture stress) but less deformable (decreased fracture strain) as phase volume increased.

A model particle for application in cheese must (1) survive the cheesemaking process, and (2) be visible in the cheese matrix. Sephadex beads (GE Healthcare Life Sciences, Pittsburgh, PA) have been used in several investigations to study filler effects in gels. Brownsey et al. (1987) published one of the earliest studies in which uncharged beads of varying rigidities were added to either a 3 or $6 \%$ gelatin system. The beads behaved as active fillers because they increased the complex gel modulus. Using beads of different sizes did not show significant particle-size effects (Brownsey et al., 1987). This is consistent with filled gel theory assuming that the particle rigidity did not change with size. Negatively charged Sephadex beads, which were thought to form electrostatic interactions with the positively charged gelatin network, caused a significant increase in the reinforcing effect (Brownsey et al., 1987).

Cheese is a complex system and, as such, interactive mechanisms between its constituent parts and structural elements are difficult to understand. Previous work suggested that milkfat acts as an active filler in cheese (Zhou and Mulvaney, 1998; Rogers et al., 2010; Yang et al., 2011). Yang et al. (2011) fit the storage modulus $\left(\mathrm{G}^{\prime}\right)$ of Cheddar cheese to 12 different theoretical models for filled gel particles and found that the models that most accurately described the cheese rheology were those that included a "crowding factor" to modify phase volume and rigidities of both phases. In this investigation, we made small-scale batches of Cheddar cheese in which Sephadex beads were substituted for milkfat. The goal was to more clearly understand the role of filler particles in cheese by adding nonmelting, spherical filler particles to simplify the system. The size of uncharged Sephadex beads was varied and related to the filled gel model.

\section{MATERIALS AND METHODS}

\section{Cheese}

Materials. All cheeses were produced at Utah State University (Logan). Starter culture DVS850, a blend of Lactococcus lactis species as frozen pellets of cell concentrate was from Chr. Hansen Inc. (Milwaukee, WI). Double-strength chymosin (Maxiren), with nominal activity of 650 international milk clotting units/mL, was from DSM Food Specialties USA Inc. (Eagleville, PA). White distilled vinegar with $5 \%$ acidity was from Sysco Corporation (Houston, TX). Neutrally charged Sephadex G-50 (supplied by Sigma-Aldrich Co., St. Louis, MO) was obtained as medium, fine, and superfine powders with nominal dry bead sizes of 50 to 150 $\mu \mathrm{m}, 20$ to $80 \mu \mathrm{m}$, and 20 to $50 \mu \mathrm{m}$, respectively, and mixed with distilled water in a 1:9 ratio and allowed to hydrate overnight at $4^{\circ} \mathrm{C}$. Cow milk (pH 6.6 to 6.7) was from the Utah State University Caine Dairy Research and Teaching Center (Wellsville, UT). Milk was processed and cheesemaking performed in the Gary Haight Richardson Dairy Products Laboratory at Utah State University. After cream separation, the skim milk $(\sim 0.2 \%$ fat $)$ was pasteurized at $73^{\circ} \mathrm{C}$ for $15 \mathrm{~s}$, and the cream ( $\sim 32 \%$ fat) was pasteurized at $68^{\circ} \mathrm{C}$ for $30 \mathrm{~min}$; both were stored overnight at $4^{\circ} \mathrm{C}$.

Milk Substrate. Sixteen kilograms of milk substrate was prepared using skim milk plus cream for the control cheeses and skim milk plus hydrated Sephadex beads (a slight excess of water was used in hydrating the beads to form a slurry and allow easier mixing) for the experimental cheeses. Control cheeses at 3 nominal fat levels were manufactured representing full-fat/filler (FF), 50\% reduced-fat/filler ( $\mathbf{R F}$ ), and low-fat/filler (LF) Cheddar cheeses; skim milk was standardized to protein to fat ratios of $0.83,1.9$, and 4.5 , respectively.

Milk substrate for the experimental cheeses corresponding to $\mathrm{FF}, \mathrm{RF}$, and $\mathrm{LF}$ were prepared by adding 80,45, and $19 \mathrm{~g}$ (dry bead weight) of hydrated Sephadex beads to $15.3,15.6$, and $15.8 \mathrm{~kg}$ of skim milk, respectively. Assuming a 9:1 weight ratio of hydrated beads to dry beads, this corresponds to milk substrate containing 4.5, 2.5, and 1.1\% (wt/wt) of hydrated Sep- 
hadex beads. Preliminary experiments predicted a loss of $\sim 20 \%$ beads into the whey during cheesemaking and the usual loss of $\sim 87 \%$ starting liquid to cheese whey (Fox et al., 2004). This was expected to produce cheeses in which the hydrated Sephadex beads would occupy $\sim 33,16$, and $6 \%$ of the final cheese volume, respectively.

Cheesemaking. Parameters for the various cheese manufacturing procedures are shown in Table 1. Skim or standardized milk was warmed to the set temperature, and $7 \mathrm{~g}$ of starter culture plus $1.8 \mathrm{~mL}$ of annatto were added. Forty minutes after adding the starter, the Sephadex slurry was added with stirring, followed immediately by addition of $3.5 \mathrm{~mL}$ of chymosin. Then, the milk was allowed to coagulate. The curd was cut when firm $(\sim 15 \mathrm{~min})$, allowed to heal, and then stirred and cooked. The whey was drained when the target curd $\mathrm{pH}$ was reached. The curds for making the LF and $\mathrm{RF}$ cheeses were washed using $\sim 2 \mathrm{~kg}$ of cold water for $10 \mathrm{~min}$, and then the curd was dry stirred until the target salting $\mathrm{pH}$ was reached. After salting, the cheese was filled into round plastic hoops and pressed at $60 \mathrm{kPa}$ overnight $(\sim 18 \mathrm{~h})$ at room temperature $(20 \pm$ $3^{\circ} \mathrm{C}$ ) into nominal blocks. Cheeses were vacuumed packaged and stored at $6^{\circ} \mathrm{C}$ for aging. Sample blocks were shipped overnight (with ice packs) to North Carolina State University (Raleigh) for rheological testing. Two replications were made; treatments were tested at 8,12 , and $18 \mathrm{wk}$.

\section{Proximate Analysis}

Sodium chloride content was measured using a chloride analyzer (model 926, Corning, Medfield, MA). Grated cheese was mixed with distilled water for 4 min and homogenized at $260 \mathrm{rpm}$ in a Stomacher 400 (Seward, UK). The slurry was filtered through Whatman No. 1 filter paper (Maidstone, UK), and the filtrate was analyzed for salt. Moisture content was determined in triplicate by weight loss using a CEM microwave oven (CEM Corp., Indian Trail, NC). Fat content was determined using the Babcock method (Marshall, 1992; method 15.8.A). All proximate analyses were completed $5 \mathrm{~d}$ after the cheese was manufactured.

\section{Microscopy}

Cheese samples were imaged using confocal scanning laser microscopy (CSLM). The method for imaging samples was similar to one used by Guinee et al. (2000). Cheese samples were held at $4^{\circ} \mathrm{C}$ until sliced into sections approximately $5 \mathrm{~mm} \times 5 \mathrm{~mm} \times 1 \mathrm{~mm}$ thick using a razor blade; samples were taken from near the edge of the cheese and from the interior. A $0.2 \%$ solution of Nile Blue A Sulfate (MP Biomedicals LLC, Solon, $\mathrm{OH})$ fluorescent dye in deionized water was filtered twice using Whatman No. 3 filter paper, and $20 \mu \mathrm{L}$ of the solution was pipetted onto the cut surface of each cheese slice. The dye was allowed to absorb into the cheese at room temperature for $10 \mathrm{~min}$. Cheese samples were then turned over (dyed cheese surface against the glass slide) onto a single-welled slide with a \#1.5 coverslip adhered to the bottom of the slide via silicone grease. Treatments were imaged on an inverted Leica TCS SP1 CSLM (Leica Inc., Bannockburn, IL) using both PL Fluotar $40.0 \times 1.00$ oil UV and HC PL Fluotar $10.0 \times 0.30$ objectives. A $488-\mathrm{nm}$ laser (to excite Nile Blue in the fat phase) and a 633-nm laser (to excite Nile Blue in the protein phase) were used sequentially

Table 1. Parameters used in converting $16 \mathrm{~kg}$ of milk substrate ${ }^{1}$ into Cheddar cheese

\begin{tabular}{|c|c|c|c|c|c|c|}
\hline \multirow[b]{2}{*}{ Parameter } & \multicolumn{6}{|c|}{ Treatment ${ }^{2}$} \\
\hline & $\mathrm{FF}$ & S-FF & $\mathrm{RF}$ & $\mathrm{S}-\mathrm{RF}$ & LF & S-LF \\
\hline Milk fat $(\%, w t / w t)$ & 3.5 & 0.2 & 1.6 & 0.2 & 0.7 & 0.2 \\
\hline Dry Sephadex added ( $\mathrm{g} / \mathrm{kg}$ of milk) & 0 & 80 & 0 & 45 & 0 & 19 \\
\hline Set temperature $\left({ }^{\circ} \mathrm{C}\right)$ & 31 & 31 & 31 & 31 & 32 & 32 \\
\hline Cooking temperature $\left({ }^{\circ} \mathrm{C}\right)$ & 38 & 38 & 36 & 36 & 36 & 36 \\
\hline Cooking time $(\min )$ & 25 & 25 & 15 & 15 & 15 & 15 \\
\hline Drain pH & 6.10 & 6.30 & 6.20 & 6.30 & 6.20 & 6.20 \\
\hline Wash water temperature $\left({ }^{\circ} \mathrm{C}\right)$ & & & 17 & 19 & 16 & 16 \\
\hline Curd temperature $\left({ }^{\circ} \mathrm{C}\right)$ & & & 27 & 27 & 26 & 26 \\
\hline Set-to-drain time (min) & 150 & 120 & 135 & 135 & 130 & 130 \\
\hline Salt $\mathrm{pH}^{3}$ & 5.45 & 5.75 & 5.80 & 5.90 & 5.95 & 5.95 \\
\hline Drain-to-salt time (min) & 70 & 70 & 40 & 55 & 50 & 50 \\
\hline Salting (g/kg of curd) & 22 & 26 & 25 & 28 & 22 & 26 \\
\hline
\end{tabular}

${ }^{1}$ Milk substrate consisted of standardized milk for the control cheeses and included both skim milk and the Sephadex bead (GE Healthcare Life Sciences, Pittsburgh, PA) slurry for the experimental cheeses.

${ }^{2}$ Treatments included full filler (FF), reduced filler (RF), and low filler (LF) fat-level cheeses and their Sephadex-containing respective counterparts (S-FF, S-RF, and S-LF).

${ }^{3}$ Values shown are for second replication. For the first replication, the salting $\mathrm{pH}$ of the cheeses was $\sim 5.85$. 
to image the samples. Emission spectra were collected from 500 to $650 \mathrm{~nm}$ for the fat phase and from 650 to $800 \mathrm{~nm}$ for the protein phase, and the resulting images were overlaid. For each cheese treatment, at least 4 samples were prepared; 2 images were taken per sample at the $10 \times$ objective and 3 images were taken per sample at the $40 \times$, resulting in a total of at least 20 images per treatment. MetaMorph software (version 7.5, Molecular Devices, Downingtown, PA) was used to analyze the area of Sephadex beads in the protein phase and the bead diameters. Specifically, the image was thresholded to convert it to binary, and the software was used to calculate the diameter of each circle (2-dimensional representation of a bead). This diameter measurement was then converted to a circular area. Overlapping or touching circles were separated using a "cut" feature that allowed manual separation of objects when necessary. Due to light reflection, pixels were occasionally missing from the edges of some circles. Measuring the diameter instead of the entire area directly circumvented the need to manually select and "join" pixels. A minimum of 100 circles was averaged for each treatment; the range in sizes was also recorded. The percentage area of circles in each image was also calculated from the total image area.

\section{Rheological Tests}

All rheological tests were conducted at 8, 12, and 18 wk of age. After opening the package, cheeses were resealed in closeable storage bags to prevent moisture loss. Tests were completed within $3 \mathrm{~d}$ of opening a package.

Small-Strain Testing. A Stresstech controlledstress rheometer (ATS Rheosystems, Bordentown, NJ) fitted with a 20-mm smooth, parallel-plate geometry was used to determine viscoelastic properties through stress sweeps, creep/recovery tests, and frequency sweeps. For each test, cheese samples, $4 \mathrm{~mm}$ thick, were trimmed to the size of the upper plate and glued to both plates with Loctite 401 cyanoacrylate glue (Loctite Corp., Rocky Hill, CT) to prevent sample slippage during testing. A thin layer of lubricant (SuperLube, Synco Chemical, Bohemia, NY) was applied to any exposed cheese edges to prevent moisture loss.

Stress sweeps were conducted to determine the linear viscoelastic region (LVR). Three samples were tested per treatment per replication. Stress sweeps were conducted at $25^{\circ} \mathrm{C}$ from 1 to $2,000 \mathrm{~Pa}$ at $10 \mathrm{~Hz}$; the temperature was regulated using a clamshell oven that was attached to the rheometer and whose 2 halves closed around the plate area. The LVR was identified by the plateau region of the complex modulus $\left(\mathbf{G}^{*}\right)$. The critical stress and strain values were identified as the point when $\mathrm{G}^{*}$ values decreased $1 \%$ from the constant plateau value.

Creep/recovery tests were conducted at 100 and 500 $\mathrm{Pa}$ on different samples. Based on the method of Rogers et al. (2009), loads were applied for $200 \mathrm{~s}$ and then removed such that the sample was allowed to recover for an additional $200 \mathrm{~s}$. Tests were conducted in triplicate per replication at each load value for each treatment. The maximum compliance $\left(\mathbf{J}_{\max }\right)$ reached before the load was removed and the maximum recovery $\left(\mathbf{J}_{\mathbf{r}}\right)$ obtained after the load was removed were recorded from each test. Percentage creep recovery (crp) was calculated using the equation from Brown et al. (2003):

$$
\begin{aligned}
& \operatorname{crp}=\frac{\mathrm{J}_{\max }-\mathrm{J}_{\mathrm{r}}}{\mathrm{J}_{\max }} \times 100 \\
& \text { and } \mathrm{J}_{\mathrm{r}}=\mathrm{J}_{\max }-\mathrm{J}_{\min },
\end{aligned}
$$

where $J_{\max }$ was the value after $200 \mathrm{~s}$ of creep, and $\mathrm{J}_{\min }$ was achieved after $200 \mathrm{~s}$ of recovery.

Frequency sweeps were conducted on replication 1 treatments from 0.01 to $10 \mathrm{~Hz}$ at $150 \mathrm{~Pa}$. The frequency sweep was repeated on a single sample at 10, 15, 20, 25, and again at $10^{\circ} \mathrm{C}$. For replication 2 , frequency sweeps were prolonged and run from 0.0016 to $10 \mathrm{~Hz}$. One frequency sweep was conducted per cheese treatment per replication in each phase of testing.

Large-Strain Rheological Tests. A 1-cycle compression test was performed to determine the structural changes of cheese at deformations beyond the LVR and before fracture; the method was adapted from van den Berg et al. (2008). Cheese was sealed in plastic storage bags to prevent moisture loss and allowed to equilibrate to room temperature $\left(22 \pm 2^{\circ} \mathrm{C}\right)$ for $12 \mathrm{~h}$. Six cheese cylinders were removed per treatment using a $15.6-\mathrm{mm}-$ diameter cork borer and cut to a length of $17 \mathrm{~mm}$. Samples were removed from the interior of the block to account for any moisture loss at the block edge. Each cheese cylinder was uniaxially compressed by $20 \%$ of the initial height (i.e., from $17 \mathrm{~mm}$ to $13.6 \mathrm{~mm}$ ). Compression was conducted using an Instron 5565 universal testing machine (Instron, Norwood, MA) with flat plates coated with mineral oil to prevent friction. The top plate compressed the cheese cylinder at $50 \mathrm{~mm} /$ min until the target strain was reached and then in the reverse direction at the same rate to allow for recovery. The area under the resultant force-deformation curve was calculated using Simpson's rule. Percentage recoverable energy $(\mathbf{R E})$ was calculated as a ratio of the area under the recovery curve $\left(\mathrm{A}_{\text {recovery }}\right.$, work recovered from decompression) over the area under the initial compression ( $\mathrm{A}_{\text {compression, }}$, work to compress): 


$$
\mathrm{RE}=\frac{\mathrm{A}_{\text {recovery }}}{\mathrm{A}_{\text {compression }}} \times 100 .
$$

\section{Statistical Analysis}

The experiment involved 2 crossed factors: filler type (4 levels) and filler volume (3 levels). A unit of cheese was produced under each of these 12 combinations and many rheological responses were measured at each of 3 different ages. This process was repeated in 2 complete "blocks." To analyze these various rheological response variables, separate linear mixed effects models were fit to each, with random effects appropriate to the design, also known as a split-plot in time complete block design. Filler type and volume were considered wholeplot factors and age a split-plot factor. In these mixed models, random effects were included for block and the interaction between the block and the whole-plot factor combination (block $\times$ volume $\times$ filler). Fixed effects were included for main effects and all possible interactions among the 3 factors. The model equation fitted to each response is given below:

$$
\begin{aligned}
Y_{i j k t}=\mu & +\alpha_{i}+\beta_{j}+(\alpha \beta)_{i j}+\tau_{t}+(\alpha \tau)_{i t}+(\beta \tau)_{j t} \\
& +(\alpha \beta \tau)_{i j t}+B_{k}+U_{i j k}+E_{i j k t},
\end{aligned}
$$

defined as follows: Term $=$ overall mean $+(\text { filler type })_{i}$ $+(\text { filler volume })_{j}+$ (filler type $\times$ filler volume $)_{i j}+$ $(\text { age })_{t}+(\text { filler type } \times \text { age })_{i t}+(\text { filler volume } \times \text { age })_{j t}$ $+(\text { filler type } \times \text { filler volume } \times \text { age })_{i j t}+(\text { block })_{k}+$ (batch) $)_{i j k}+(\text { error })_{i j k t}$. In this equation, $i, j$, and $t$ represent filler type, volume, and age, respectively; $k=$ 1,2 is an index for the 2 blocks, $B_{1}$ and $B_{2}$; and $U_{i j k}$ is a random effect for the experimental parent mass of cheese. All statistical analysis was conducted using SAS statistical software (version 9.2, SAS Institute Inc. Cary, NC).

\section{RESULTS AND DISCUSSION}

\section{Selection of Filler Particles and Volumes and Time Points}

Sephadex beads were designed for use in chromatography and separation experiments. The beads are made from cross-linked polydextrans and are available in different sizes $(20-300 \mu \mathrm{m})$, porosities, and charges. The beads differ markedly from milkfat in that they do not melt and are perfectly spherical, larger than native milkfat globules, and comprised largely of water after rehydration. Therefore, the use of Sephadex beads as a filler in lieu of milkfat greatly simplifies the complex cheese system in an effort to understand the effect of filler properties. The relative rigidity of the bead relates to the bead's porosity and the amount of water it absorbs during hydration. Because Sephadex is traditionally used for filtering, it may adsorb other compounds from the complex matrix, presumably before gelation is complete. Brownsey et al. (1987) observed that gelatin was excluded from all grades of Sephadex, but Langley et al. (1990) found that whey protein, used as the suspending network, adsorbed into the porous particles. Langley et al. (1990) further noted that Sephadex-filled whey protein gels failed at or near the particle-protein interface, unlike whey protein gels filled with hydrophobic particles, which failed adjacent to the particle surface. The authors interpreted these results to mean that adsorption produced a strong interaction between filler and matrix.

Sephadex G-50 beads were chosen for this experiment because they are an intermediate of the "stiff" (G-25, G-50, and G-75) beads tested by Brownsey et al. (1987) and were expected to exhibit reinforcing effects. Filler volumes were chosen to correspond to commercial FF, RF, and LF cheese. According to US Food and Drug Administration regulation, FF Cheddar cheese must legally contain $50 \%$ fat on a dry basis (FDA, 2014a; 21CFR101.13); that is, 30.5 to $33 \%$ (wt/ wt) milkfat for cheeses with 39 to $34 \%$ moisture, respectively. An RF cheese must contain at least $25 \%$ less fat than the FF counterpart, and LF cheese contains 3 $\mathrm{g}$ of fat or less per 50-g reference amount (FDA, 2014b; 21CFR101.62). Target filler volumes (fat or Sephadex beads) for the cheeses were $33 \%$ for $\mathrm{FF}$ cheese, $16 \%$ for a counterpart $50 \%-\mathrm{RF}$ cheese, and $6 \%$ for the counterpart LF cheese. Sampling times of 8, 12, and 18 wk of age were picked because these allow time for the curds to be "well knit" (Creamer and Olson, 1982), thus providing the homogeneous mass that is important for rheological and mechanical testing. It also covers the period in which most Cheddar cheese is consumed in the United States.

\section{Cheese Appearance and Composition}

All treatments were uniform, but Sephadex-filled cheeses were characterized by a much darker, deeperorange color than the control cheese because of the difference in light-scattering properties of Sephadex beads. Although the precise reason is not known, annatto could be absorbed into the bead, versus only surface effects with milkfat, and the contribution of different light-scattering properties. We observed a slight difference between replicates regarding the salting $\mathrm{pH}$ (Table 1 , footnote 3 ). In the first replication of RF Sephadex cheeses and LF cheeses (control and 
Sephadex), acid production was faster than expected. Thus, the $\mathrm{pH}$ after draining decreased faster, meaning the $\mathrm{pH}$ had already decreased to $\sim 5.85$ by the time of salting. Consequently, the final $\mathrm{pH}$ of these cheeses ( $\mathrm{pH} 4.95-5.0)$ was slightly lower than that of the second replication cheeses ( $\mathrm{pH}$ 5.1-5.25). Less culture was added when making the second replication of cheese so that $\mathrm{pH}$ could be more closely monitored. These differences in $\mathrm{pH}$ are not expected to have significantly affected the results.

The composition of each treatment is reported in Table 2. Despite the aforementioned batch differences, the salt content and $\mathrm{pH}$ were relatively constant across all treatments; consistency in the latter is particularly important because $\mathrm{pH}$ significantly affects cheese structure and breakdown (Creamer and Olson, 1982; Watkinson et al., 2001). Sephadex treatments were consistently higher than controls in both moisture content and moisture-to-protein ratio. Typically, higher moisture would make a cheese less firm, but the Sephadex treatments remained firm (discussed in upcoming sections) even though their moisture content remained high. This is because some water in these treatments is associated with the Sephadex beads themselves, which absorb water during hydration and swell. It is unclear how much of the moisture is associated with Sephadex beads versus protein versus unbound water. Thus, with water-containing beads, unlike milkfat, notable changes in composition occurred within and between treatments. However, the water in the beads was part of the dispersed particle phase.

To relate the results to filled-gel models, weight percentages were converted to volume percentages using the same method as used in Yang et al. (2011). In both that work and this work, the densities of milkfat, protein, and water at $25^{\circ} \mathrm{C}$ were taken to be $0.915,1.317$, and $0.995 \mathrm{~g} / \mathrm{mL}$, respectively, based on temperature studies done by Sahin and Sumun (2006). Because Sephadex beads swell with water, their density was assumed to be that of water for purposes of calculating the volume percentage of milkfat. The volume of the Sephadex beads themselves was calculated by other means, which will be discussed in an upcoming section. Both the weight and volume percentages of milkfat are presented in Table 2. The x-axis of all figures is based on the measured total filler volume.

The control cheeses closely matched the target filler values (Table 2). As indicated by the standard deviations, the fat content varied somewhat between batches, particularly for the RF Sephadex treatments, but the fat content among treatments in each batch was similar. The skim milk contained $\sim 0.2 \%$ fat and the goal when making particle-filled cheeses was to minimize fat content as much as possible such that primarily the ef- fect of Sephadex beads would be seen. Fat represented $24.7,24.6$, and $9.26 \%$ of the total filler amount for Sephadex LF, RF, and FF treatments, respectively. The FF control did slightly exceed the maximum moisture content ( $41.2 \pm 0.5$ vs. $39.0 \% \mathrm{wt} / \mathrm{wt})$ allowed under the standard of identity for Cheddar cheese (FDA, 2014c; 21CFR133.113). This variation is not expected to affect the conclusions of the experiment as they are based on filler volume effects.

\section{Microscopy and Quantification of Sephadex Volume}

Sephadex beads neither absorbed dye nor reflected light and were therefore easily viewed via CSLM. No differences were observed in the fat or protein structure on the basis of age or position (sampling from outside edge of the cheese block versus inside core). Magnification of $40 \times$ was used to search for any abnormalities but none were observed. Treatments were viewed at $10 \times$ magnification to view the spread of beads over a larger field. Sephadex beads were identified in images on the basis of their size, perfect spherical dimensions, lack of color (did not absorb dye), and absence from control images (Figure 1a). The size of Sephadex beads ranged from 20 to $150 \mu \mathrm{m}$; the size of milkfat globules is 0.1 to $10 \mu \mathrm{m}$ (Walstra, 1999).

Cheese microstructure images were used both to view the spread of beads and to determine the volume of beads retained in the experimental treatments. The percentage area occupied by a 2 -dimensional Sephadex slice in the images is proportional to the percentage volume occupied by a sphere of equivalent diameter (Russ, 2005). If only 2 beads overlapped, the computer software was used to divide the spheres, and the areas were treated as 2 separate bead measurements. This was an easy task at the LF concentrations because few beads overlapped, and when they did, it was as easy to separate them as dividing an "8" into 2 circles (Figure 1c). The task was exceedingly difficult at FF concentrations, particularly among the smallest (superfine) beads, due to the high degree of overlap. It was often difficult to determine how many beads were in a "clump" (Figure 1b). Nevertheless, microscopy was chosen as the best method for calculating the volume of beads retained in the cheese because, as previously mentioned, the Sephadex beads exchange fluids with the surround gel phase so the initial volume of added beads cannot be assumed to represent volume in the cheese. It should be noted that the 2-dimensional circles seen in the images represent imaging slices at various location in a bead with a range of diameters (not monodispersed particles). This makes it exceedingly difficult to determine an accurate size distribution. We used low magnification to view as wide a field 
Table 2. Targeted and measured compositions of cheeses

\begin{tabular}{|c|c|c|c|c|c|c|c|c|c|c|c|}
\hline \multirow[b]{2}{*}{ Filler $^{1}$} & \multicolumn{3}{|c|}{ Target } & \multicolumn{8}{|c|}{ Measured } \\
\hline & $\begin{array}{l}\text { Sephadex }{ }^{2} \\
(\% \text { vol/vol })\end{array}$ & $\begin{array}{c}\mathrm{Fat}^{3} \\
(\% \mathrm{vol} / \mathrm{vol})\end{array}$ & $\begin{array}{c}\text { Total } \\
\text { filler }(\%)\end{array}$ & $\begin{array}{l}\text { Moisture }^{4} \\
\text { (\% wt/wt) }\end{array}$ & $\begin{array}{c}\text { Salt }^{4} \\
(\% \mathrm{wt} / \mathrm{wt})\end{array}$ & $\begin{array}{c}\text { Fat }^{4} \\
(\% \mathrm{wt} / \mathrm{wt})\end{array}$ & $\begin{array}{c}\mathrm{Fat}^{5} \\
(\% \mathrm{vol} / \mathrm{vol})\end{array}$ & $\mathrm{pH}^{4}$ & $\begin{array}{l}\text { Protein }^{6} \\
\text { (\% wt/wt) }\end{array}$ & $\begin{array}{c}\text { Moisture: } \\
\text { Protein }\end{array}$ & $\begin{array}{l}\text { Total filler } \\
\text { (\% vol/vol) }\end{array}$ \\
\hline \multicolumn{12}{|c|}{ Low-fat/filler } \\
\hline Milkfat & 0 & 6 & 6 & $53.6 \pm 0.8$ & $1.9 \pm 0.3$ & $6.3 \pm 1.1$ & 7.7 & $5.0 \pm 0.1$ & $36.3 \pm 1.6$ & 1.48 & 7.7 \\
\hline Superfine & 6 & 0 & 6 & $58.9 \pm 0.8$ & $2.0 \pm 0.3$ & $1.5 \pm 0.7$ & 1.8 & $5.0 \pm 0.2$ & $34.7 \pm 1.3$ & 1.70 & 7.8 \\
\hline Fine & 6 & 0 & 6 & $57.5 \pm 0.7$ & $1.9 \pm 0.0$ & $1.8 \pm 1.1$ & 2.2 & $5.1 \pm 0.2$ & $36.0 \pm 1.5$ & 1.60 & 8.2 \\
\hline Medium & 6 & 0 & 6 & $56.5 \pm 0.1$ & $1.9 \pm 0.3$ & $1.5 \pm 0.7$ & 1.9 & $5.1 \pm 0.1$ & $37.2 \pm 0.3$ & 1.52 & 7.9 \\
\hline \multicolumn{12}{|c|}{ Reduced-fat/filler } \\
\hline Milkfat & 0 & 16 & 16 & $49.5 \pm 2.0$ & $1.9 \pm 0.0$ & $16.0 \pm 0.7$ & 19.0 & $5.2 \pm 0.1$ & $30.6 \pm 2.7$ & 1.62 & 19.0 \\
\hline Superfine & 16 & 0 & 16 & $57.3 \pm 3.9$ & $2.0 \pm 0.3$ & $4.0 \pm 2.8$ & 5.0 & $5.1 \pm 0.2$ & $32.6 \pm 1.3$ & 1.76 & 21.0 \\
\hline Fine & 16 & 0 & 16 & $57.8 \pm 0.9$ & $2.1 \pm 0.1$ & $3.8 \pm 2.5$ & 4.7 & $5.1 \pm 0.2$ & $32.3 \pm 1.6$ & 1.79 & 20.7 \\
\hline Medium & 16 & 0 & 16 & $55.4 \pm 2.2$ & $2.0 \pm 0.2$ & $4.8 \pm 2.5$ & 6.0 & $5.1 \pm 0.2$ & $33.8 \pm 0.1$ & 1.63 & 22.0 \\
\hline \multicolumn{12}{|c|}{ Full-fat/filler } \\
\hline Milkfat & 0 & 33 & 33 & $41.2 \pm 0.5$ & $1.9 \pm 0.3$ & $29.3 \pm 1.1$ & 33.9 & $5.2 \pm 0.1$ & $25.6 \pm 1.0$ & 1.62 & 33.9 \\
\hline Superfine & 33 & 0 & 33 & $58.7 \pm 0.3$ & $2.3 \pm 0.0$ & $2.3 \pm 1.1$ & 2.9 & $5.0 \pm 0.3$ & $31.1 \pm 0.7$ & 1.89 & 35.9 \\
\hline Fine & 33 & 0 & 33 & $55.5 \pm 0.2$ & $2.3 \pm 0.3$ & $2.8 \pm 1.1$ & 3.6 & $5.1 \pm 0.2$ & $33.8 \pm 1.6$ & 1.64 & 36.6 \\
\hline Medium & 33 & 0 & 33 & $53.8 \pm 0.4$ & $2.2 \pm 0.1$ & $2.8 \pm 0.4$ & 3.6 & $5.1 \pm 0.4$ & $35.6 \pm 0.1$ & 1.55 & 36.6 \\
\hline
\end{tabular}

${ }^{1}$ The source of milk fat was either skim milk or skim milk + cream. All Sephadex beads were of the G-50 series (GE Healthcare Life Sciences, Pittsburgh, PA).

${ }^{2}$ Sephadex volume was determined after accounting for bead hydration and loss of beads to whey stream during cheddaring.

${ }^{3}$ Skim milk provided the only source of fat $(\sim 0.2 \%$ fat pre-cheddaring $)$ in the Sephadex cheeses.

${ }^{4}$ Entries represent the average value from 2 batches \pm SD between batches.

${ }^{5}$ Conversion from weight to volume was made using an average milkfat density of $0.915 \mathrm{~g} / \mathrm{mL}$ at $25^{\circ} \mathrm{C}$ based on similar work by Yang et al. (2011).

${ }^{6}$ Calculated on a mass balance basis assuming moisture + added salt + fat + protein + dry Sephadex $+2 \%$ (ash and lactic acid) $=100 \%$, where dry Sephadex was calculated based on microscopy image analysis.

${ }^{7}$ Total filler volume $=($ actual fat volume $)+($ Sephadex bead volume as confirmed by microscopy $)$. 

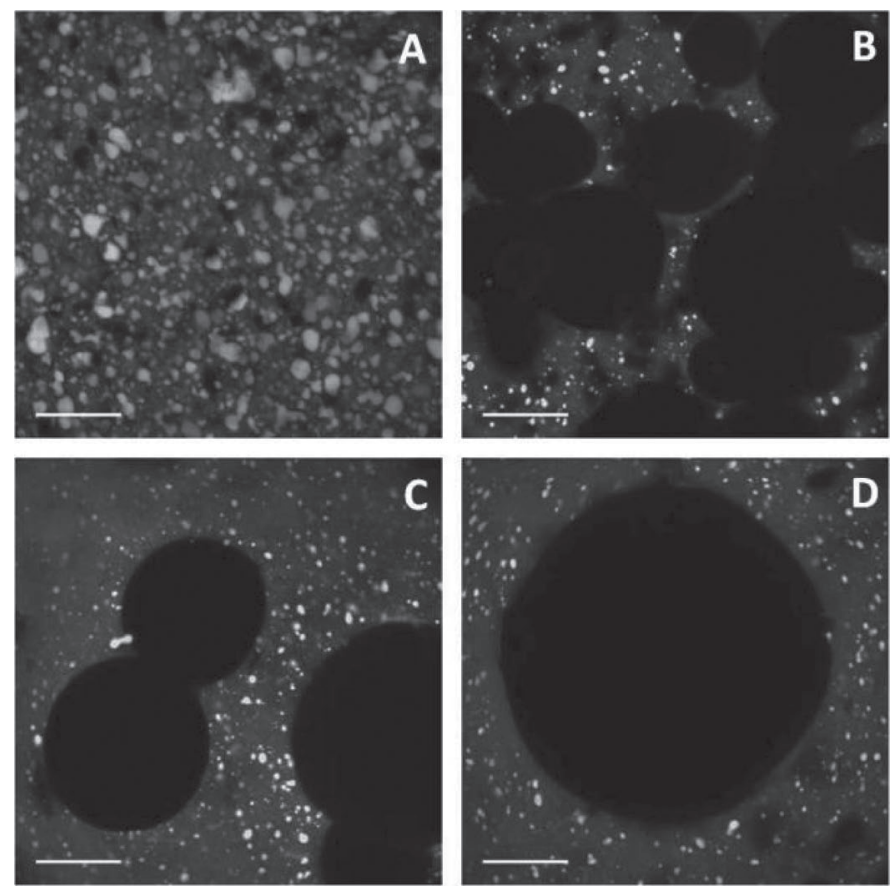

Figure 1. Microstructures of cheeses containing fat and Sephadex beads (filler; GE Healthcare Life Sciences, Pittsburgh, PA). Protein phase is dark gray background; milkfat $(0.1$ to $10 \mu \mathrm{m})$ is light gray; Sephadex beads are black (do not absorb dye) circles. $\mathrm{A}=$ full fat (FF)-control, B = FF-superfine (20 to $50 \mu \mathrm{m}$ dry bead size), $\mathrm{C}=\mathrm{FF}$ fine $(20$ to $80 \mu \mathrm{m})$, and $\mathrm{D}=\mathrm{FF}$-medium $(50$ to $150 \mu \mathrm{m})$. Treatments at $8 \mathrm{wk}$ of age. Scale bars are $50 \mu \mathrm{m}$.

as possible and viewed multiple sections to increase the quantity of measured spheres to obtain as representative a value as possible. Given the good agreement between target and measured filler volume (Table 2), we assumed that the target Sephadex filler volumes were achieved within reason. This assumption is similar to that made by Madziva et al. (2006), who used light microscopy to approximate recovery of alginate-pectin capsules in Cheddar cheese. However, both Sephadex beads and milkfat act as filler particles. Therefore, all figures and analysis were based on measured total filler volume (Table 2 ).

\section{Statistics}

To characterize the factorial effects of the experimental factors of filler type (Sephadex superfine, fine, and medium sizes, and milkfat), volume, and age on the various rheological properties measured, $P$-values for tests of main effects and interactions are given in Table 3. For most rheological responses, the observed filler type $\times$ volume interaction effect was not significant, but the main effects of filler type and volume were significant, suggesting that the effects of these 2 factors are plausibly additive. Age, however, was significant only for RE. Therefore, values from 8,12 , and $18 \mathrm{wk}$ were averaged together for all parameters except RE. Because interaction responses were not significant, values in this paper are reported for only main effects.

The mean response was then compared across levels of each of these 2 factors after averaging over levels for all other factors (data not shown). Analysis of the means showed that the effect of filler type was often manifested by a difference between control and any of the other 3 filler types. Furthermore, means for many responses were ordered such that the level for fine Sephadex lay between levels for superfine and medium Sephadex, although this ordering was rarely statistically significant under the applied parameters. The effect of volume was usually that the mean response at the FF level differed significantly from the mean at LF or RF.

\section{Rheological Properties}

The critical strain point (Figure 2) can be considered the level of strain where damage or long-term relaxations take place in the network; larger critical strain values signify a longer LVR. We detected no differences due to filler type, just filler volume, with the FF treat-

Table 3. $P$-values for tests of effects of main factors (filler type, filler volume, and treatment age) and interactions for rheological properties of cheeses $^{1,2}$

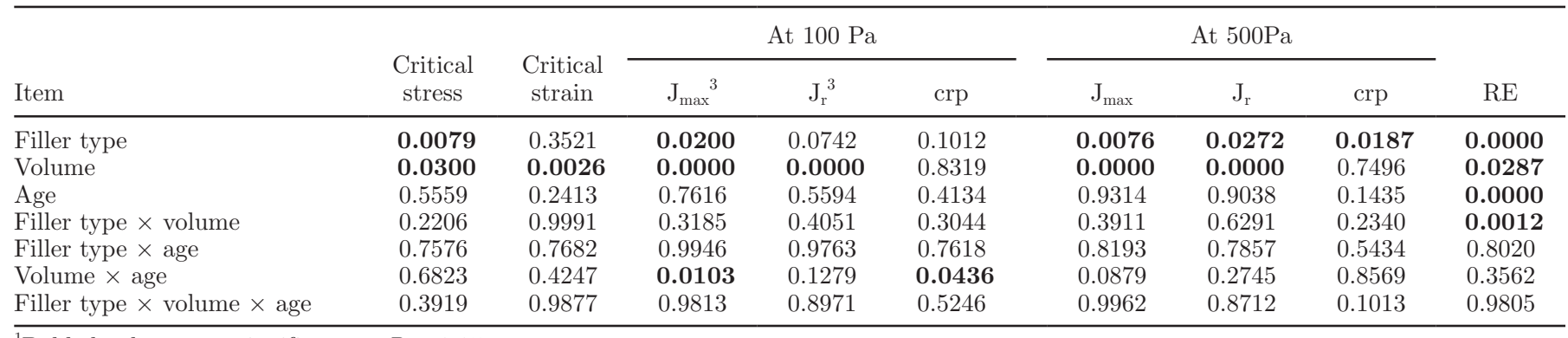

${ }^{1}$ Bolded values were significant at $P<0.05$.

${ }^{2} \mathrm{~J}_{\max }=$ maximum compliance; $\mathrm{J}_{\mathrm{r}}=$ maximum recovery; $\mathrm{crp}=$ percentage creep recovery; $\mathrm{RE}=$ recoverable energy.

${ }^{3}$ The $P$-values for compliance are from analysis of log-transformed data. 


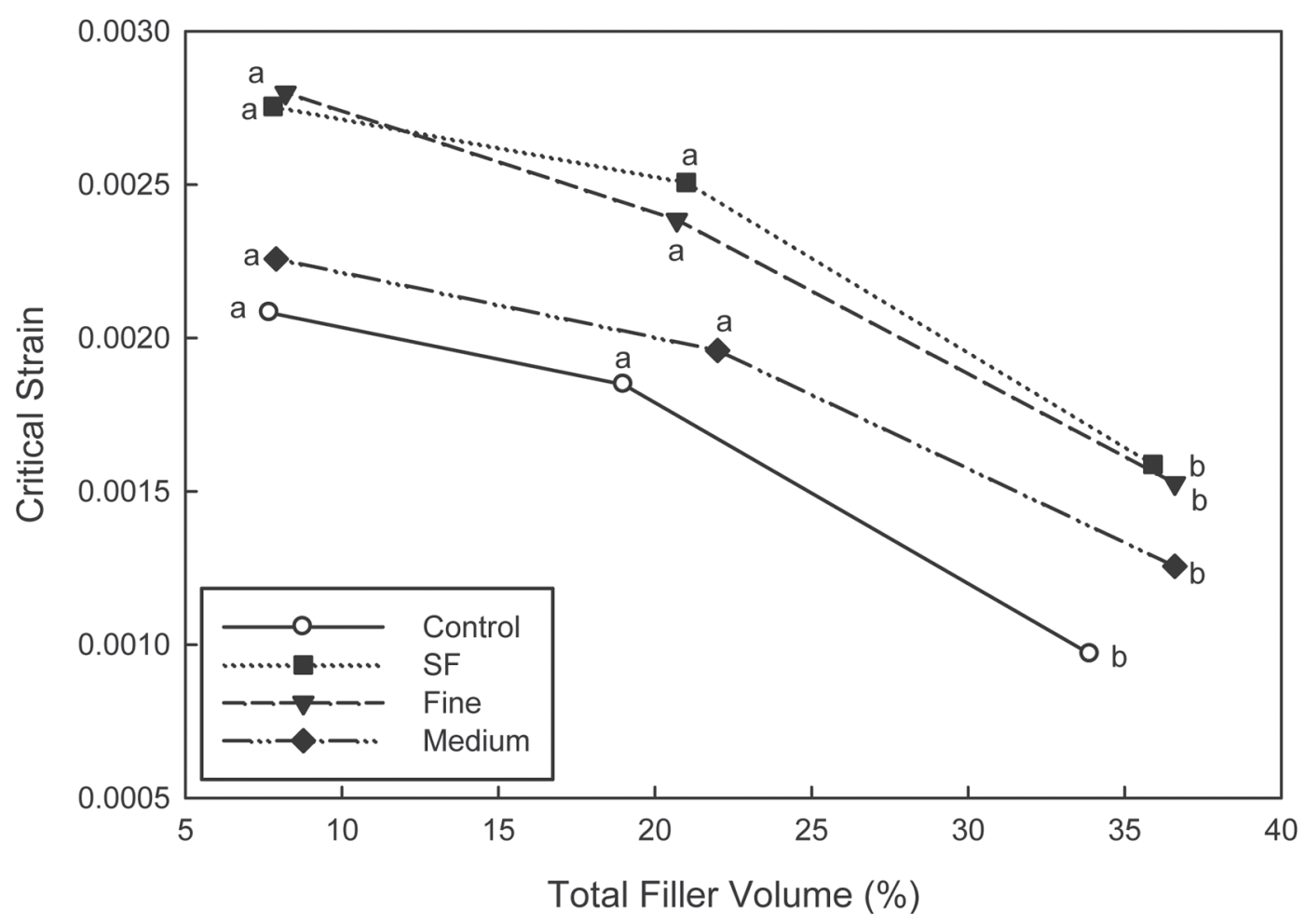

Figure 2. Critical strain (averaging over age, which was not statistically significant) as a function of filler particle type [control, superfine (SF), fine, and medium] and filler volume. Filler type had no significant effect $(P<0.05)$; data points (averaged values) with different lowercase letters were significantly different for the effect of filler volume at $P<0.05$. Samples were analyzed at $25^{\circ} \mathrm{C}$.

ment volumes being significantly lower in critical strain (Figure 2). This showed that filler particles-regardless of type- provide sites for stress concentration and initiate fracture, thereby lowering the strain required for initial fracture. These results agreed with those of previous filled gel work (Sala et al., 2009).

We detected no statistical difference in $\mathrm{J}_{\max }$ between an applied load of 100 and $500 \mathrm{~Pa}$; therefore, results are only shown for $\mathrm{J}_{\max }$ at $500 \mathrm{~Pa}$ (Figure 3). The effects of volume and filler type were significant. Medium filler particles produced a more rigid structure (lower $\left.\mathrm{J}_{\max }\right)$ than superfine particles. As seen with critical stress, the RF and LF treatments did not differ significantly within a single filler type. However, as phase volume increased above $25 \%, \mathrm{~J}_{\max }$ decreased, indicating that the $\mathrm{FF}$ samples were firmer. Decreasing $\mathrm{J}_{\max }$ has been significantly related to increases in sensory firmness (Brown et al., 2003). Lozinsky et al. (1992) also observed the same volume-dependent results upon adding Sephadex beads of varying rigidities and sizes to poly(vinyl alcohol)-based cryogels. Because $J_{\max }$ is inversely related to $G^{*}$, the decreasing $J_{\max }$ values as phase volume increased implies a reinforcing effect as the volume of active filler increases. The filler material influenced the extent of this reinforcing effect, and superfine and fine particles produced $\mathrm{J}_{\max }$ values closest to that of the FF control.

The compliance after recovery $\left(\mathrm{J}_{\min }\right)$ and the amount of compliance recovered during the recovery phase $\left(\mathrm{J}_{\mathrm{r}}\right)$ showed no consistent trends with either filler type or volume (data not shown). The reasons why no clear trends appeared are unclear but could be related to the complexity of elements contributing to relaxations that either will not recover or required longer than $200 \mathrm{~s}$ for recovery.

Mechanical spectra as a function of temperature are shown in Figure 4. In the control samples, the $10^{\circ} \mathrm{C}$ curve obtained after heating followed by a cool-down did not overlay with the initial $10^{\circ} \mathrm{C}$ curve. This hysteresis between curves is most likely associated with melting and reforming of the fat crystalline phase; the greater storage modulus values after cooling (open circles in Figure 4) indicate that the sample was more rigid after cooling. Unlike milkfat, however, Sephadex beads do not melt, deform, or pool together upon heating and no perceptible hysteresis was observed between the two $10^{\circ} \mathrm{C}$ curves for the cheese containing Sephadex beads, and the range of change in $\mathrm{G}^{\prime}$ was narrower. Note that values for the Sephadex-filled cheese ranged from approximately 100 to $1,000 \mathrm{kPa}$, whereas those of 


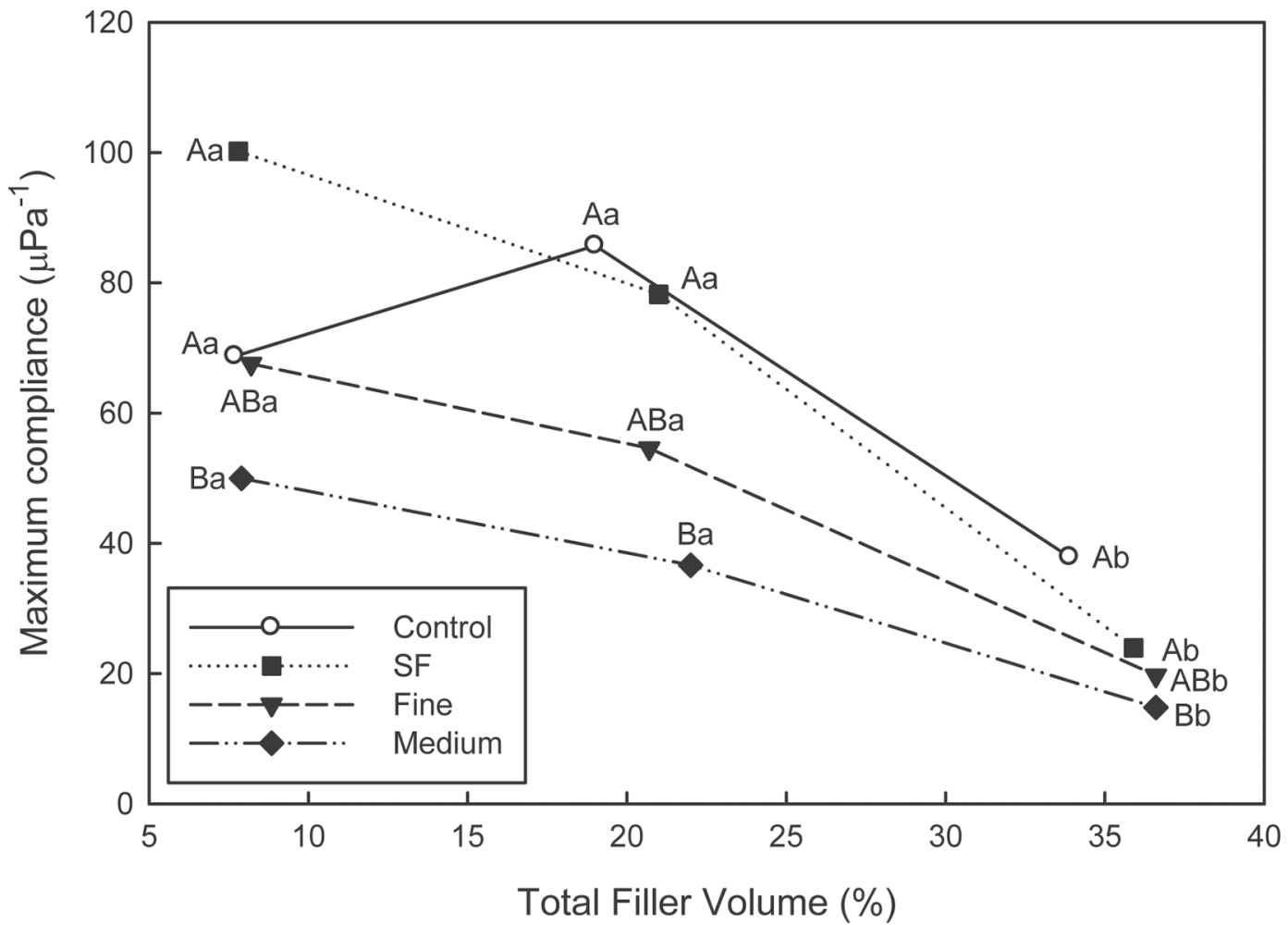

Figure 3. Effect of filler type [control, superfine (SF), fine, and medium] and volume on maximum compliance $\left(\mathrm{J}_{\max }\right)$, under load of 500 $\mathrm{Pa}$, for cheeses (averaging over age, which was not statistically significant). Data points (averaged values) with different uppercase letters were significantly different for the effect of filler type at $P<0.05$; data points with different lowercase letters were significantly different for the effect of filler volume at $P<0.05$. Samples were analyzed at $25^{\circ} \mathrm{C}$.

the control cheese exceeded $1,000 \mathrm{kPa}$ (Figure 4). This shows that firmness of Sephadex-filled cheese would vary less with temperature than that of its FF counterpart. The change in storage modulus of Sephadexfilled cheese reflects a softening of the gel matrix as temperature was increased. This has been observed in other protein gels such as bovine serum albumin (Clark and Lee-Tuffnell, 1986).

The interplay between filler volume effect and temperature is highlighted in Figure 5. Regardless of filler type, the FF treatments exhibit the greatest storage modulus and the highest degree of change with temperature. This suggests that both milkfat and Sephadex beads are active fillers in the cheese matrix. This was most apparent at $10^{\circ} \mathrm{C}$, and the differences tended to disappear by $25^{\circ} \mathrm{C}$. This is opposite to the effect seen with LF treatments. There, all Sephadex-filled treatments were firmer than the control. This reflects the relative contribution of fat to the firmness of each cheese.

Recoverable energy differentiated samples on the basis of filler volume and type (Figure 6). We detected an increase in RE with Sephadex filler and coinciding decrease in $\mathrm{RE}$ with increased fat phase. Consequently, the FF control had lowest RE, probably because of the ability of fat to dissipate energy by viscous flow. Sephadex beads are an elastic polymer network, whereas milkfat is in various degrees of liquid and crystalline states, and the liquid state is very inelastic. The medium particle size Sephadex had the greatest RE, whereas the superfine and fine particles were similar (Figure $6)$. It is not clear why the medium range of particle size produced this effect; it may be that there is some other property of these particles as a function of their manufacture and not just size. According to van Vliet and Walstra (1995), total deformation energy is a summation of energy associated with elastic storage, viscoelastic dissipation, frictional dissipation, and fracture. Assuming no difference in nature of the gel network, elastic energy storage in the protein network should be consistent for all filler types at a single filler volume. Therefore, elastic energy storage in these cheeses would vary most with filler viscoelasticity. Our results coincide with those seen with other gels; for example, van den Berg et al. (2008) concluded that RE differentiated mixed whey protein isolate-polysaccharide gels on the basis of filler volume and type. 

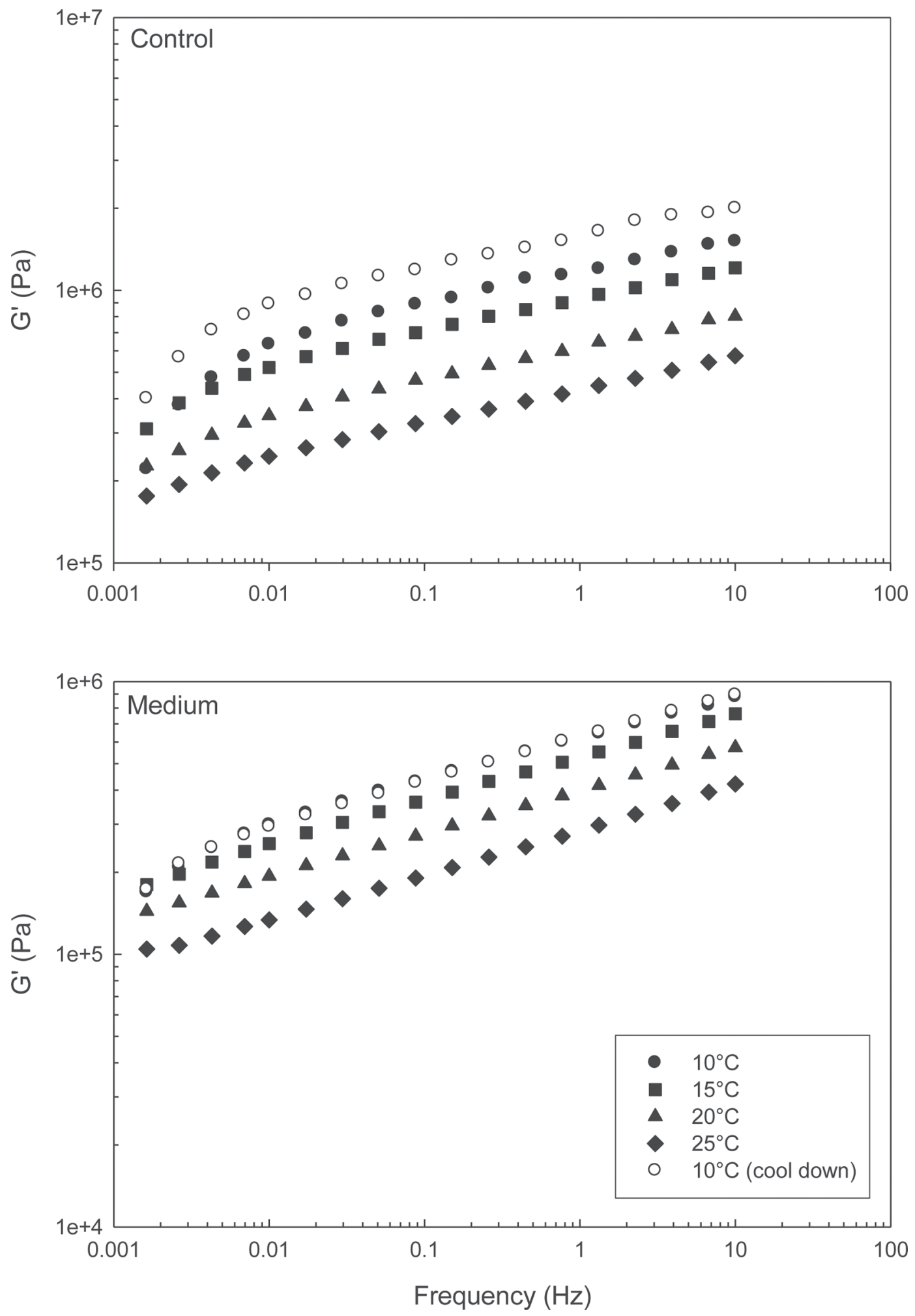

Figure 4. Mechanical spectra of representative full fat (FF)-control and medium-size Sephadex beads (FF-medium; GE Healthcare Life Sciences, Pittsburgh, PA) samples after 18 wk of age. Tested samples were from replication $2 . \mathrm{G}^{\prime}=$ storage modulus. 


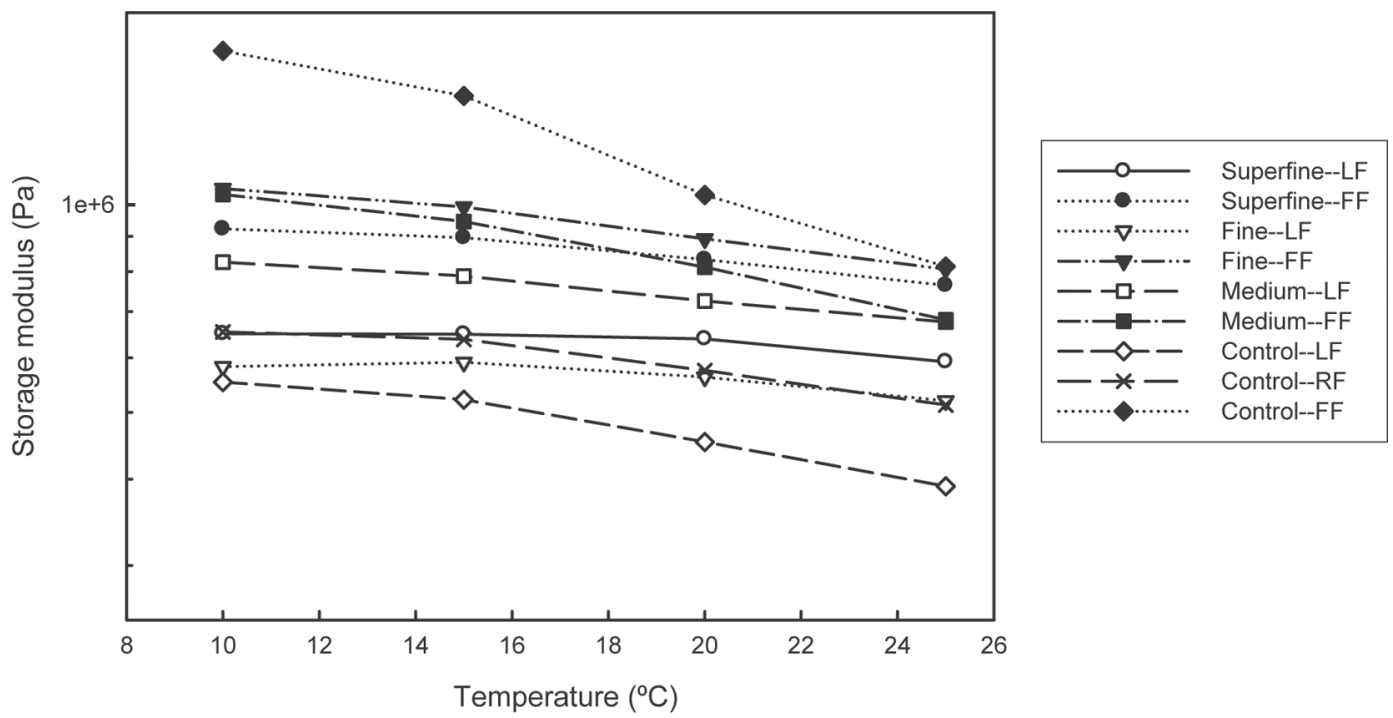

Figure 5. Effect of temperature and phase volume on storage modulus $\left(\mathrm{G}^{\prime}\right)$. Values, averaged across all ages and both replications, were obtained from frequency sweeps at a frequency of $10 \mathrm{~Hz}$. LF $=$ low fat; $\mathrm{FF}=$ full fat; $\mathrm{RF}=$ reduced fat; fillers $=$ control, superfine, fine, medium Sephadex beads.

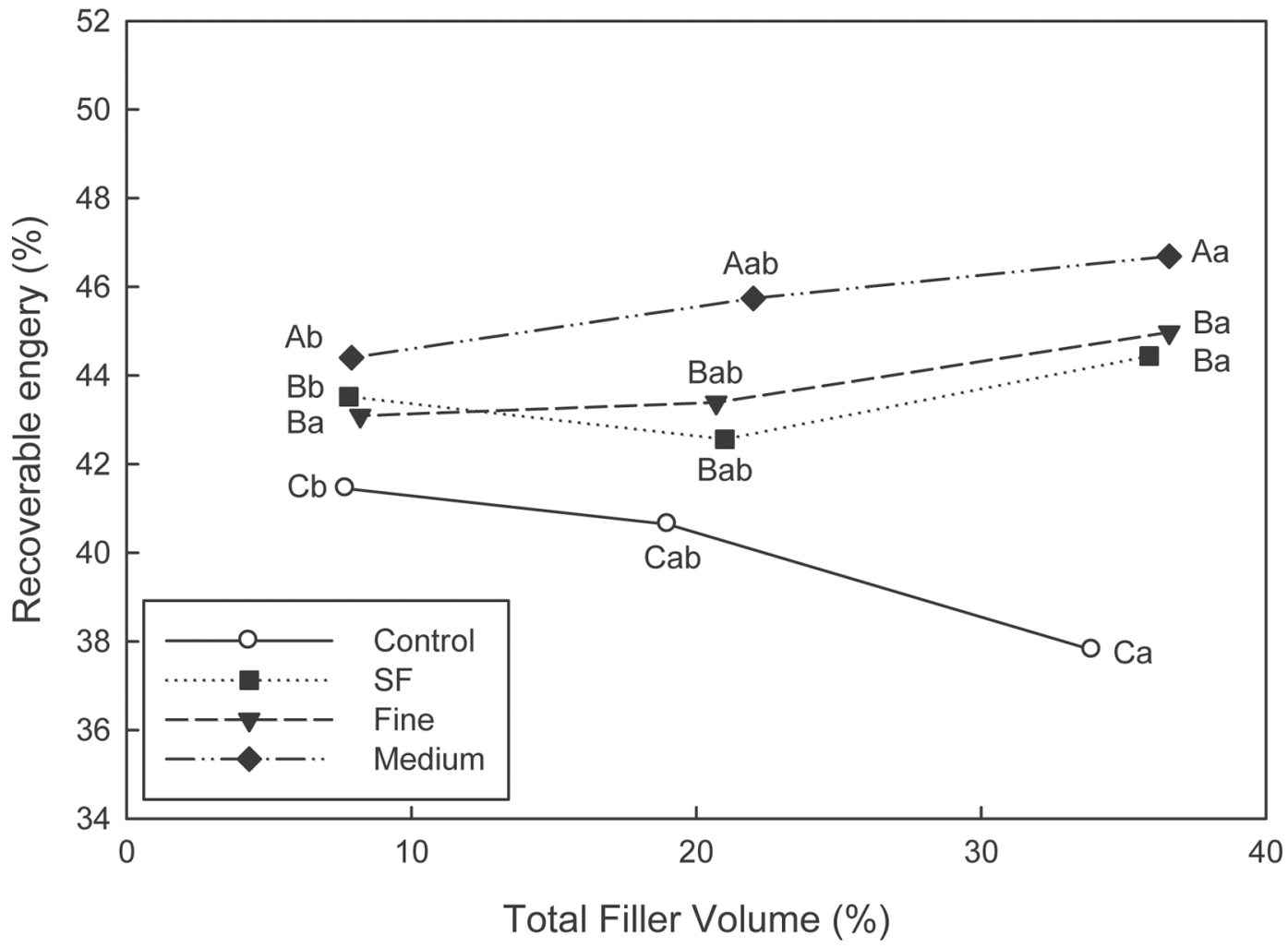

Figure 6. Effect of filler type [control, superfine (SF), fine, and medium] and phase volume on percentage recoverable energy (RE) at 12 wk of age. Data points (averaged values) with different uppercase letters were significantly different for the effect of filler type at $P<0.05$; data points with different lowercase letters were significantly different for the effect of filler volume at $P<0.05$. Samples were analyzed at $22^{\circ} \mathrm{C}$.. 

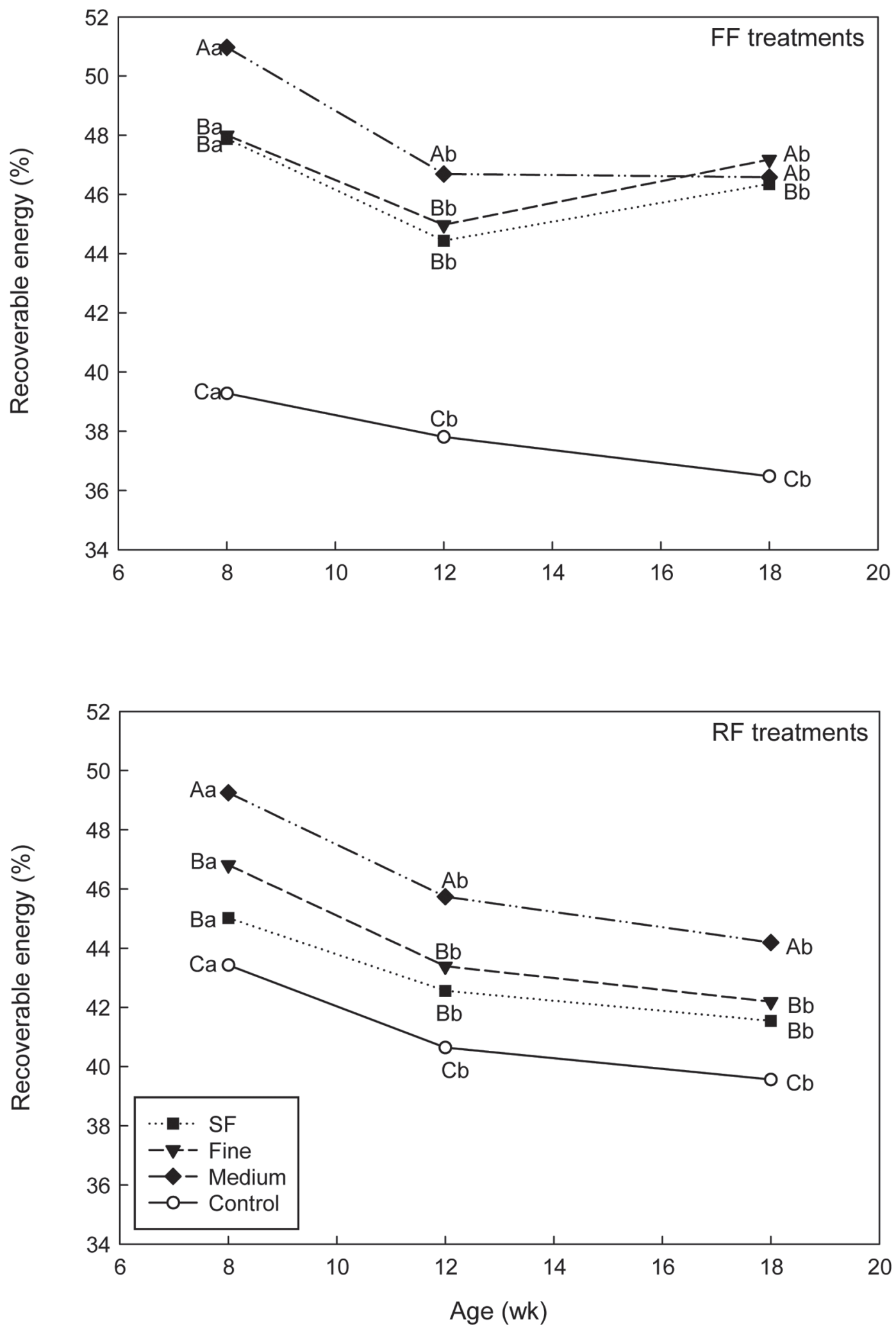

Figure 7. Effect of age and filler volume (reduced filler vs. full filler) on percentage recoverable energy (RE; averaged values). Data points (averaged values) with different uppercase letters were significantly different for the effect of filler type at $P<0.05$; data points with different lowercase letters were significantly different for the effect of filler volume at $P<0.05 . \mathrm{SF}=$ superfine; $\mathrm{FF}=$ full fat/filler; $\mathrm{RF}=\mathrm{reduced}$ fat/ filler. 


\section{Effect of Age, Filler Type, and Filler Size}

Age (i.e., 8 to 18 wk of storage) had no significant effect on any of the properties determined within the LVR for any treatment, regardless of filler type, size, or charge. Cheddar curds are known to be well knit by 8 wk of age (Creamer and Olson, 1982), so that was the minimal age investigated. A similar lack of clear ageassociated trend in rheological properties determined in the linear viscoelastic region was observed in our previous investigation where the a constant gel phase (similar protein:water ratio) was mixed with different amounts of a fat phase and aged (Rogers et al., 2010). Moreover, age-associated trends were less apparent in cheeses containing $20 \%$ or less fat. Rheological measurements made in the LVR are designed to not damage the gel network structure so it does not account for weakening of the structure and is inherently less sensitive to age-associated changes.

Testing beyond the LVR showed that RE decreased with age; this decrease was more consistent in RF treatments than in FF treatments (Figure 7). This implies that the protein network was changing with age such that processes of friction, viscous flow, or small fractures were not dissipating more energy. Fenelon and Guinee (2000) have also found large-strain compression tests to be correlated with age in reduced-fat Cheddar cheeses, but they did not conduct any small-strain analyses.

Some general trends can be observed in the rheological results. First, particle phase volume, and not particle size, alters the critical strain (Figure 2). Second, particle size is important to $\mathrm{J}_{\max }$ and RE. Milkfat globules (0.1 to $10 \mu \mathrm{m}$ ) are much smaller than the Sephadex beads, but beads with diameters ranging from 20 to $80 \mu \mathrm{m}$ (fine and superfine) were similar to the control cheeses. However, the largest beads, the medium Sephadex beads with diameters ranging from 50 to $150 \mu \mathrm{m}$, were often either significantly different from all other treatments or similar to only the next closest bead in size, the fine treatment. This suggests that bead size may affect the rheology of filled gels, although there appears to be a threshold size at which these effects are noticeable. It is possible, however, that size may cause different rheological properties of the Sephadex particle. Previous studies have published mixed results on filler particle size. For instance, Brownsey et al. (1987) found no size effects from Sephadex beads, but Lozinsky et al. (1992) found that creep compliance decreased as Sephadex bead diameter increased, although bead diameter did not affect the apparent instantaneous shear modulus. The results of Lozinsky et al. (1992) match those of the current study in that respect. Ross-Murphy and Todd (1983) studied gelatin gels filled with glass particles of different shapes and found that both shape and volume affect rheology. Using a fruit jam matrix, however, Genovese et al. (2010) found that the size of pectin particles did not affect the rheology of that filled gel. As previously mentioned, the filled gel model assumes that filler particles are spherical and accounts only for filler volume, not shape or size.

\section{CONCLUSIONS}

Cheese is a complex system, and its rheological and mechanical properties depend on processing conditions such as $\mathrm{pH}$, rate of acid development, salt (ionic strength), degree of cross-linking by calcium phosphate, proteolysis, and more. Nevertheless, this work showed that we can simplify our view of the system and begin to build a model. Within and beyond the range of linear viscoelastic properties, cheese made using milkfat as the filler particles and cheese made using Sephadex filler particles exhibited similar behavior that closely corresponded to predictions made using the filled gel model. Thus, we confirmed that the mechanical properties of cheese depend on the rheological properties of both the gel matrix and filler particle and on the volume within the cheese occupied by the filler particles. Filler particles that are rigid and do not melt will result in mechanical properties of cheese that are similar to milkfat at cold temperatures but different at room temperature $\left(25^{\circ} \mathrm{C}\right)$. The ideal particle would melt or soften at body temperature, much like a full-fat cheese.

\section{ACKNOWLEDGMENTS}

Support from the North Carolina Agricultural Research Service (Raleigh), Dairy Management Inc. as administered by the Dairy Research Institute (Rosemont, IL), and Southeast Dairy Foods Research Center (Raleigh) are gratefully acknowledged. The use of trade names in this publication does not imply endorsement by the North Carolina Agricultural Research Service of the products named nor criticism of similar ones not mentioned. This project was part of a collaboration with Utah State University (Logan), and we thank the Department of Nutrition and Food Sciences at Utah State, and Carl Brothersen in particular, for the production and aging of the cheeses. The technical support of Sharon Ramsey and Paige Luck of North Carolina State University (Raleigh) is gratefully acknowledged.

\section{REFERENCES}

Ahmed, S., and F. R. Jones. 1990. A review of particulate reinforcement theories for polymer composites. J. Mater. Sci. 25:49334942.

Brown, J. A., E. A. Foegeding, C. R. Daubert, M. A. Drake, and M. Gumpertz. 2003. Relationships among rheological and sensorial properties of young cheeses. J. Dairy Sci. 86:3054-3067. 
Brownsey, G. J., H. S. Ellis, M. J. Ridout, and S. G. Ring. 1987. Elasticity and failure in composite gels. J. Rheol. (N.Y.N.Y.) 31:635-649.

Chen, J., and E. Dickinson. 1998. Viscoelastic properties of proteinstabilized emulsions: Effect of protein-surfactant interactions. J. Agric. Food Chem. 46:91-97.

Chen, J., and E. Dickinson. 1999. Effect of surface character of filler particles on rheology of heat-set whey protein emulsion gels. Colloids Surf. B Biointerfaces 12:373-381.

Childs, J. L., and M. A. Drake. 2009. Consumer perception of fat reduction in cheese. J. Sens. Stud. 24:902-921.

Clark, A. H., and C. D. Lee-Tuffnell. 1986. Gelation of globular proteins. Pages 216-224 in Functional Properties of Food Macromolecules. J. R. Mitchell and D. A. Ledward, ed. Elsevier Applied Science, London, UK.

Creamer, L. K., and N. F. Olson. 1982. Rheological evaluation of maturing Cheddar cheese. J. Food Sci. 47:631-636., 646.

Dickinson, E. 2012. Emulsion gels: The structuring of soft solids with protein-stabilized oil droplets. Food Hydrocoll. 28:224-241.

Drake, M. A., R. E. Miracle, and D. J. McMahon. 2010. Impact of fat reduction on flavor and flavor chemistry of Cheddar cheeses. J. Dairy Sci. 93:5069-5081.

FDA (Food and Drug Administration). 2014a. 21CFR101.13: Nutrient content claims - general principles. Accessed June 29 2014. http://www.accessdata.fda.gov/scripts/cdrh/cfdocs/cfcfr/ CFRSearch.cfm?fr $=101.13$.

FDA (Food and Drug Administration). 2014b. 21CFR101.62: Nutrient content claims for fat, fatty acid, and cholesterol content of food Accessed June 29, 2014. http://www.accessdata.fda.gov/scripts/ cdrh/cfdocs/cfcfr/CFRSearch.cfm?fr $=101.62$

FDA (Food and Drug Administration). 2014c. 21CFR133.113: Cheese and related cheese products - Cheddar cheese. Accessed Aug. 18 2014. http://www.accessdata.fda.gov/scripts/cdrh/cfdocs/cfcfr/ CFRSearch.cfm?fr $=133.113$

Fenelon, M. A., and T. P. Guinee. 2000. Primary proteolysis and textural changes during ripening in Cheddar cheeses manufactured to different fat contents. Int. Dairy J. 10:151-158.

Fox, P. F., P. L. H. McSweeney, T. M. Cogan, and T. P. Guinee. 2004. Cheese: Chemistry, Physics and Microbiology. Vol. 1. 3rd ed. Elsevier, London, UK.

Genovese, D. B., A. Q. Ye, and H. Singh. 2010. High methoxyl pectin/ apple particles composite gels: Effect of particle size and particle concentration on mechanical properties and gel structure. J. Texture Stud. 41:171-189.

Guinee, T. P., M. A. E. Auty, C. Mullins, M. O. Corcoran, and E. O. Mulholland. 2000. Preliminary observations on effects of fat content and degree of fat emulsification on the structure-functional relationship of Cheddar-type cheese. J. Texture Stud. 31:645-663.

Kerner, E. H. 1956. The elastic and thermo-elastic properties of composite media. Proc. Phys. Soc. Lond. B. 8:808-813.

Langley, K. R., M. L. Green, and A. Martin. 1990. Rheological and structural properties of model composite foods. Pages 301-303 in Third European Rheology Conference and Golden Jubilee Meeting of the British Society of Rheology. D. R. Oliver, ed. Elsevier Applied Science, London, UK.

Lozinsky, V. I., A. I. Zubov, V. K. Kulakova, E. F. Titova, and S. V. Rocozhin. 1992. Study of cryostructurization of polymer systems.
IX. Poly(vinyl alcohol) cryogels filled with particles of crosslinked dextran gel. J. Appl. Polym. Sci. 44:1423-1435.

Madziva, H., K. Kailasapathy, and M. Phillips. 2006. Evaluation of alginate-pectin capsules in Cheddar cheese as a food carrier for the delivery of folic acid. Lebenson. Wiss. Technol. 39:146-151.

Marshall, R. T. 1992. Standard Methods for the Examination of Dairy Products. American Public Health Association, New York, NY.

Ring, S., and G. Stainsby. 1982. Filler reinforcement of gels. Prog. Food Nutr. Sci. 6:323-329.

Rogers, N. R., M. A. Drake, C. R. Daubert, D. J. McMahon, T. K. Bletch, and E. A. Foegeding. 2009. The effect of aging on low-fat, reduced-fat, and full-fat Cheddar cheese texture. J. Dairy Sci. 92:4756-4772

Rogers, N. R., D. J. McMahon, C. R. Daubert, T. K. Berry, and E. A. Foegeding. 2010. Rheological properties and microstructure of Cheddar cheese made with different fat contents. J. Dairy Sci. 93:4565-4576

Ross-Murphy, S. B., and S. Todd. 1983. Ultimate tensile measurements of filled gelatin gels. Polymer (Guildf.) 24:481-486.

Russ, J. C. 2005. Image Analysis of Food Microstructure. CRC Press, Boca Raton, FL.

Sahin, S., and S. G. Sumun. 2006. Physical Properties of Foods. Springer Science + BusinessMedia, LLC, New York, NY

Sala, G., T. van Vliet, M. C. Stuart, F. van de Velde, and G. A. van Aken. 2009. Deformation and fracture of emulsion-filled gels: Effect of gelling agent concentration and oil droplet size. Food Hydrocoll. 23:1853-1863.

van den Berg, L., A. L. Carolas, T. van Vliet, E. van der Linden, M. A. J. S. van Boekel, and F. van de Velde. 2008. Energy storage controls crumbly perception in whey proteins/polysaccharide mixed gels. Food Hydrocoll. 22:1404-1417.

van der Poel, C. 1958. On the rheology of concentrated dispersions. Rheol. Acta 1:198-205.

van Vliet, T. 1988. Rheological properties of filled gels. Influence of filler matrix interaction. Colloid Polym. Sci. 266:518-524.

van Vliet, T., and P. Walstra. 1995. Large deformation and fracture behavior of gels. Faraday Discuss. 101:359-370.

Visser, J. 1991. Factors affecting the rheological and fracture properties of hard and semi-hard cheese. Pages 49-61 in Rheological and Fracture Properties of Cheese. P. Walstra, ed. Bull. No. 268. International Dairy Federation, Brussels, Belgium.

Walstra, P. 1999. Dairy Technology: Principles of Milk Properties and Processes. Marcel Dekker Inc., New York, NY.

Walstra, P. 2003. Physical Chemistry of Foods. Marcel Dekker Inc., New York, NY.

Watkinson, P., C. Coker, R. Crawford, C. Dodds, K. Johnston, A. McKenna, and N. White. 2001. Effect of cheese $\mathrm{pH}$ and ripening time on model cheese textural properties and proteolysis. Int Dairy J. 11:455-464.

Yang, X., N. R. Rogers, T. K. Berry, and E. A. Foegeding. 2011. Modeling the rheological properties of Cheddar cheese with different fat contents at various temperatures. J. Texture Stud. 42:331-348.

Zhou, N., and S. J. Mulvaney. 1998. The effect of milk fat, the ratio of casein to water, and temperature on the viscoelastic properties of rennet casein gels. J. Dairy Sci. 81:2561-2571. 